\title{
A infecção pela Covid-19 provoca manifestações bucais? Uma revisão de litertura
}

\author{
Does Covid-19 infection cause oral manifestations? A litigation review \\ ¿La infección por Covid-19 causa manifestaciones orales? Una revisión de litigio
}

Recebido: 14/05/2021 | Revisado: 23/05/2021 | Aceito: 26/05/2021 | Publicado: 11/06/2021

\author{
Guilherme Silva Furtado \\ ORCID: https://orcid.org/0000-0002-8796-1634 \\ Universidade Federal do Maranhão, Brasil \\ E-mail: gfurtado.ufma@gmail.com \\ Beatriz Leal de Siqueira Menezes \\ ORCID: https://orcid.org/0000-0003-3198-7189 \\ Universidade Federal do Maranhão, Brasil \\ E-mail: beatriz.menezes@discente.ufma.br \\ Kaytlhen Kayllen Carvalho de Menezes \\ ORCID: https://orcid.org/0000-0002-6345-8874 \\ Universidade Federal do Maranhão, Brasil \\ E-mail: kkc.menezes@discente.ufma.br \\ Maria Áurea Lira Feitosa \\ ORCID: https://orcid.org/0000-0002-9177-2369 \\ Universidade Federal do Maranhão, Brasil \\ E-mail: aurea.maria@ufma.br \\ Darlon Martins Lima \\ ORCID: https://orcid.org/0000-0001-9113-1206 \\ Universidade Federal do Maranhão, Brasil \\ E-mail: darlon.martins@ufma.br \\ Rosana Costa Casanovas \\ ORCID: https://orcid.org/0000-0002-6871-3491 \\ Universidade Federal do Maranhão, Brasil \\ E-mail: rosana.casanovas@ufma.br
}

\section{Resumo}

Diversas pesquisas encontram-se em andamento pelo mundo nos últimos meses em busca de respostas sobre o SARSCoV-2, causador da pandemia gerada pela Covid-19. Esta é uma doença de rápido e fácil contágio, visto que a principal forma de transmissão é por contato direto com gotículas salivares contendo o vírus. Tem-se demonstrado o aparecimento de vários sinais bucais em pacientes acometidos pela Covid-19, levando-se a teoria de que a infecção viral seja responsável pelo aparecimento de manifestações bucais e outras infecções secundárias por outros microorganismos patogênicos. O objetivo desse estudo é condensar as informações sobre a presença e tipos de manifestações orais relatadas nos pacientes com Covid-19. Realizou-se uma busca nas bases PubMed, SciELO, LILACS, Google acadêmico utilizando descritores, estratégias e critérios pré-estabelecidos por dois avaliadores, de forma independente. As estratégias de pesquisa identificaram 439 artigos. Após triagem dos trabalhos, 426 foram excluídos e 13 selecionados para compor esta revisão. Concluiu-se que é possível associar o surgimento de manifestações orais com a Covid-19. Porém, não se tem comprovação que são alterações secundárias ao tratamento ou se estão diretamente relacionadas ao coronavírus.

Palavras-chave: Coronavírus; Covid-19; Manifestações orais.

\section{Summary}

Several surveys have been underway around the world in recent months in search of answers about SARS-CoV-2, the cause of the pandemic generated by Covid-19. This is a disease of quick and easy contagion, since the main form of transmission is through direct contact with salivary droplets containing the virus. The appearance of several oral signs in patients affected by Covid-19 has been demonstrated, leading to the theory that viral infection is responsible for the appearance of oral manifestations and other secondary infections by other pathogenic microorganisms. The aim of this study is to condense information about the presence and types of oral manifestations reported in patients with Covid19. A search was carried out in the PubMed, SciELO, LILACS, Google academic databases using descriptors, strategies and criteria pre-established by two evaluators, independently. The research strategies identified 439 articles. After screening the papers, 426 were excluded and 13 selected to compose this review. It was concluded that it is possible to associate the appearance of oral manifestations with Covid-19. However, there is no evidence that they are changes secondary to treatment or if they are directly related to the coronavirus.

Keywords: Coronavirus; Covid-19; Oral manifestations. 


\section{Resumen}

En los últimos meses se han realizado varias encuestas en todo el mundo en busca de respuestas sobre el SARS-CoV2, la causa de la pandemia generada por Covid-19. Se trata de una enfermedad de contagio rápido y fácil, ya que la principal forma de transmisión es a través del contacto directo con las gotitas de saliva que contienen el virus. Se ha demostrado la aparición de varios signos orales en pacientes afectados por Covid-19, lo que lleva a la teoría de que la infección viral es responsable de la aparición de manifestaciones orales y otras infecciones secundarias por otros microorganismos patógenos. El objetivo de este estudio es condensar información sobre la presencia y tipos de manifestaciones orales reportadas en pacientes con Covid-19. Se realizó una búsqueda en las bases de datos académicas PubMed, SciELO, LILACS, Google utilizando descriptores, estrategias y criterios preestablecidos por dos evaluadores, de forma independiente. Las estrategias de investigación identificaron 439 artículos. Después de examinar los artículos, se excluyeron 426 y se seleccionaron 13 para componer esta revisión. Se concluyó que es posible asociar la aparición de manifestaciones orales con Covid-19. Sin embargo, no hay evidencia de que sean cambios secundarios al tratamiento o si están directamente relacionados con el coronavirus.

Palabras llave: Coronavirus; Covid-19; Manifestaciones orales.

\section{Introdução}

A Doença do Coronavírus de 2019 (Covid-19) é uma infecção causada pelo novo Coronavírus da Síndrome Respiratória Aguda Grave 2 (SARS-CoV-2). Essa patologia foi relatada pela primeira vez em dezembro de 2019 na cidade de Wuhan, província de Hubei, na China e se espalhou rapidamente pelo mundo (L. Li et al., 2020; Wang, Horby, Hayden \& Gao, 2020).

Devido à ameaça para a segurança da saúde pública internacional, a Organização Mundial da Saúde (OMS) declarou estado de pandemia em 11 de março de 2020 (Who, 2020). Atualmente não existe um tratamento específico para patologia, (Ouassou, 2020) e há uma maior preocupação com pessoas idosas, cardiopatas, diabéticas, obesas e indivíduos que fazem uso de altas doses de corticosteróides pelo elevado risco de morte ou exacerbação da doença (Lucena, Santos, Lima, Borborema \& Silva, 2020; Li et al. 2020).

Os sintomas clínicos mais comuns apresentados pelos pacientes com Covid-19 são hipertemia, tosse, mialgia ou fadiga, expectoração e dispneia. Outras condições incluem dores de cabeça ou tontura, diarreia, náusea, vômito, ageusia, anosmia e em casos mais graves pneumonia, contudo, a maioria dos pacientes são assintomáticos. Além disso, exames laboratoriais podem mostrar quadros de linfocitopenia, aumento da proteína $\mathrm{C}$ reativa, aumento da desidrogenase láctica e leucocitopenia (Lechien, 2020; X. Li et al., 2020).

A maioria desses indícios, quando presentes, aparecem após um período médio de 5.2 dias de incubação do vírus (Rothan \& Byrareddy, 2020). Sabe-se que a principal forma de contágio é por contato direto com gotículas suspensas no ambiente geradas pela fala, espirro ou tosse de pessoas infectadas e a colonização inicial ocorre em células da cavidade oral, nariz ou olhos (Giudice, 2020).

Também tem-se demonstrado o aparecimento de vários sinais e sintomas bucais em pacientes acometidos pela Covid19, levando-se a teoria de que a infecção viral seja responsável pelo aparecimento de manifestações bucais e outras infecções secundárias por outros microorganismos patogênicos (Sanabria, Bermúdez, Veja \& Jiménez, 2020; Behzad, Khalili, Amiri, Zartab \& Aflatoonian, 2020).

Deste modo, o presente artigo tem como objetivo realizar uma revisão da literatura científica para avaliar se a Covid19 provoca manifestações bucais nas pessoas acometidas.

\section{Metodologia}

A busca eletrônica de artigos foi realizada em maio de 2021 nas plataformas PubMed, Scientific Electronic Library Online (SciELO), Literatura Latino-Americana, do Caribe em Ciências da Saúde (LILACS) e Google acadêmico, envolvendo estudos publicados a qualquer ano, sem restrições de idioma e país. Os descritores utilizados foram " Oral manifestations" e 
"COVID-19", adquiridos do diretório dos Descritores em Ciências da Saúde (DeCS), usados em combinação com auxílio do operador booleano "AND”. A Tabela 1 expressa os resultados obtidos na pesquisa realizada nas bases de dados mencionadas. Foram eliminados trabalhos sem resumo completo e com acesso restrito.

Tabela 1: Resultados do levantamento efetuado nas bases de dados.

\begin{tabular}{ccccc}
\hline Descritores & PUBMED & SciELO & LILACS & $\begin{array}{c}\text { Google } \\
\text { acadêmico }\end{array}$ \\
\hline "Oral & 42 & 13 & 5 & 379 \\
manifestations" & & & \\
AND "COVID- & & & \\
$19 "$ & & 439 & \\
\hline Total & & & \\
\hline
\end{tabular}

Fonte: Autores.

A investigação inicial se deu por meio da leitura dos títulos e resumos das publicações. Como critérios de inclusão, os artigos teriam que relacionar a manifestações bucais que surgiram durante a infecção por Covid-19. Foram excluídos artigos duplicados. Logo, nesta fase, foram filtrados apenas artigos que tinham em seus títulos ou resumos alguma afinidade com as palavras-chaves escolhidas. Todas as buscas foram realizadas por 2 avaliadores independentes.

\section{Resultados}

Após procura nas bases de dados foram encontrados 439 artigos. Feita a análise, 420 trabalhos foram excluídos por serem duplicados ou por não relacionarem Covid-19 com a saúde bucal em seu título e resumo. Posteriormente, mais 6 publicações também foram excluídas depois da leitura do trabalho em sua íntegra por não se adequarem ao objetivo do estudo. Por fim, 13 trabalhos foram utilizados para compor esta revisão.

As principais informações dos 13 trabalhos selecionados ao final da última etapa do processo de seleção são apresentadas na Tabela 2. Foi possível associar a infecção da Covid-19 a um quadro de surgimento de alterações bucais. 
Research, Society and Development, v. 10, n. 7, e0710716081, 2021

(CC BY 4.0) | ISSN 2525-3409 | DOI: http://dx.doi.org/10.33448/rsd-v10i7.16081

Tabela 2. Síntese das principais informações de cada artigo selecionado.

\begin{tabular}{|c|c|c|c|c|c|c|}
\hline & ANO & REVISTA & AUTORES & $\begin{array}{l}\text { TIPO DE } \\
\text { ESTUDO }\end{array}$ & RESULTADOS & CONCLUSÃO \\
\hline $\begin{array}{c}\text { Oral } \\
\text { manifestations } \\
\text { of COVID-19 } \\
\text { disease: A } \\
\text { review article }\end{array}$ & 2020 & $\begin{array}{l}\text { Dermatolog } \\
\text { ic Therapy }\end{array}$ & $\begin{array}{l}\text { Behzad Iranmanesh, } \\
\text { Maryam Khalili, Rezvan } \\
\text { Amiri, Hamed Zartab, } \\
\text { Mahin Aflatoonian }\end{array}$ & $\begin{array}{c}\text { Revisão de } \\
\text { literatura }\end{array}$ & $\begin{array}{l}\text { Úlceras, erosões, bolhas, vesículas, pústulas, língua } \\
\text { fissurada ou com ausência de papilas em algumas } \\
\text { áreas, máculas, pápulas, placas, halitose, } \\
\text { candidíase, sangramento espontâneo da mucosa } \\
\text { foram algumas das lesões encontradas nos } \\
\text { pacientes incluídos no estudo. Apareceram entre } 4 \\
\text { dias e } 12 \text { semanas após a remissão dos sintomas. A } \\
\text { maioria das lesões apareceu na língua, seguida pela } \\
\text { mucosa labial. } \\
\text { As manifestações orais apresentaram-se de forma } \\
\text { dolorosa com sensação de ardência e prurido. }\end{array}$ & $\begin{array}{l}\text { Lesões herpéticas, lesões na mucosa e } \\
\text { candidíase foram as mais comuns no } \\
\text { estudo. Pode-se concluir que a idade } \\
\text { avançada do paciente e o grau de } \\
\text { evolução da Covid-19, influenciaram no } \\
\text { aparecimento de lesões na cavidade } \\
\text { bucal. Além disso, houve fatores de risco } \\
\text { para o aparecimento das mesmas, como } \\
\text { higiene oral deficiente, estresse, infecções } \\
\text { oportunistas, diabetes mellitus, } \\
\text { imunossupressão e problemas vasculares. }\end{array}$ \\
\hline $\begin{array}{l}\text { Manifestacione } \\
\text { s orales y } \\
\text { maxilofaciales } \\
\text { asociadas a la } \\
\text { COVID-19. } \\
\text { Revisión de la } \\
\text { literatura }\end{array}$ & 2020 & $\begin{array}{c}\text { Acta } \\
\text { Odontológi } \\
\text { ca } \\
\text { Colombiana }\end{array}$ & $\begin{array}{l}\text { Erika Alexandra Parra, } \\
\text { Sanabria } \\
\text { Melisa Bermúdez, } \\
\text { Claudia Patricia Peña } \\
\text { Veja, } \\
\text { Andrés Rueda Jiménez. }\end{array}$ & $\begin{array}{l}\text { Revisão de } \\
\text { literatura. }\end{array}$ & $\begin{array}{l}\text { Foram descritos distúrbios como disgeusia, } \\
\text { parotidite, alterações na mucosa oral, úlceras, } \\
\text { lesões eritematosas, petéquias, bolhas. Também foi } \\
\text { descrita a presença de gengivite ulcerativa } \\
\text { necrosante, xerostomia, papilas linguais } \\
\text { proeminentes e lesões labiais. Entretanto, não se } \\
\text { pode concluir que há relação direta entre tais } \\
\text { patologias e a Covid-19. Todas estavam } \\
\text { possivelmente relacionadas à infecção viral ou } \\
\text { reinfecção, aos fármacos utilizados no tratamento, à } \\
\text { posição durante a intubação e à própria intubação. }\end{array}$ & $\begin{array}{l}\text { Pode-se concluir que pacientes com } \\
\text { Covid-19 podem apresentar alterações } \\
\text { orais. Entretanto, ainda são necessários } \\
\text { mais estudos para saber se há relação } \\
\text { direta entre a infecção viral e as } \\
\text { patologias orais. }\end{array}$ \\
\hline
\end{tabular}


Research, Society and Development, v. 10, n. 7, e0710716081, 2021

(CC BY 4.0) | ISSN 2525-3409 | DOI: http://dx.doi.org/10.33448/rsd-v10i7.16081

\begin{tabular}{|c|c|c|c|c|c|c|}
\hline $\begin{array}{l}\text { Aphthous-like } \\
\text { stomatitis } \\
\text { of COVID-19 } \\
\text { patients: } \\
\text { case report and } \\
\text { review of } \\
\text { evidence }\end{array}$ & 2020 & $\begin{array}{c}\text { Brazilian } \\
\text { Journal of } \\
\text { Oral } \\
\text { Sciences }\end{array}$ & $\begin{array}{c}\text { Nuraldeen Maher Al- } \\
\text { Khanati, Abanoub Riad, } \\
\text { Mhd Eyad Sahloul, } \\
\text { Miloslav Klugar }\end{array}$ & $\begin{array}{l}\text { Relato de } \\
\text { caso e } \\
\text { revisão de } \\
\text { literatura. }\end{array}$ & $\begin{array}{c}1 \text { paciente e seus familiares apresentaram lesões } \\
\text { orais e ardência bucal após a COVID-19, o que } \\
\text { sugere que haja alguma predisposição genética para } \\
\text { esses sintomas com relação à COVID-19. } \\
14 \text { pacientes apresentaram lesões orais e na } \\
\text { mucosa, no palato mole e lábios. Todos os } \\
\text { pacientes relataram dor associada às lesões. }\end{array}$ & $\begin{array}{c}\text { As lesões podem estar associadas à } \\
\text { predisposição genética em relação à } \\
\text { COVID-19. Lesões orais dolorosas são } \\
\text { comuns em pacientes com a imunidade } \\
\text { comprometida e pode ser uma provável } \\
\text { complicação da COVID-19. }\end{array}$ \\
\hline $\begin{array}{c}\text { Manifestações } \\
\text { orais em } \\
\text { pacientes } \\
\text { infectados com } \\
\text { sars COV-2 }\end{array}$ & 2020 & $\begin{array}{l}\text { Brazilian } \\
\text { Journal of } \\
\text { Developme } \\
\text { nt }\end{array}$ & $\begin{array}{c}\text { Jeferson Luis de } \\
\text { Oliveira Stroparo, } \\
\text { Luciana Aparecida de } \\
\text { Oliveira Pereira Lyra, } \\
\text { Allan Abuabara, Kesly } \\
\text { Mary Ribeiro Andrades, } \\
\text { Isabela Ribeiro } \\
\text { Madalena, Erika } \\
\text { Calvano Küchler, } \\
\text { Camila Paiva Perin, } \\
\text { Flares Baratto Filho, } \\
\text { Tatiana Miranda } \\
\text { Deliberator. }\end{array}$ & $\begin{array}{l}\text { Relato de } \\
\text { caso clínico }\end{array}$ & $\begin{array}{c}\text { Este estudo mostrou } 5 \text { casos de lesões orais em } \\
\text { pacientes com diagnóstico de Covid-19. Os } \\
\text { pacientes apresentavam ulcerações, lesões } \\
\text { vesiculopapulares, lesões papilares, eritema lingual, } \\
\text { lesões tipo ceratose e placa branca. Lábios, língua, } \\
\text { mucosa labial, palato e gengiva foram afetados. }\end{array}$ & $\begin{array}{l}\text { Se comprovada essa hipótese, ao observar } \\
\text { essas manifestações bucais, os } \\
\text { profissionais de saúde, principalmente os } \\
\text { cirurgiões-dentistas, poderiam } \\
\text { encaminhar esses pacientes para exames e } \\
\text { tratamento adequado. }\end{array}$ \\
\hline $\begin{array}{l}\text { Alterações do } \\
\text { sistema } \\
\text { estomatognátic } \\
\text { o frente À } \\
\text { COVID-19 - } \\
\text { uma revisão } \\
\text { integrativa }\end{array}$ & 2020 & $\begin{array}{l}\text { Brazilian } \\
\text { Journal of } \\
\text { Health } \\
\text { Review }\end{array}$ & $\begin{array}{l}\text { Luana Taques, } \\
\text { Marcelo Carlos } \\
\text { Bortoluzzi, Bruna Carla } \\
\text { Karpinski, Sabrina } \\
\text { Brigola, Jéssica Cristina } \\
\text { de Mattos, Paulyne } \\
\text { Rodachinski. }\end{array}$ & $\begin{array}{c}\text { Revisão de } \\
\text { literatura }\end{array}$ & $\begin{array}{l}\text { Em relação às alterações bucais encontradas nos } \\
\text { trabalhos publicados a respeito da temática, } \\
\text { dezesseis }(76 \%) \text { deles citam as disfunções } \\
\text { gustativas - ageusia, hipogeusia, disgeusia - como } \\
\text { sintoma da infecção por SARS-CoV-2. As } \\
\text { alterações de olfato também foram bastante } \\
\text { reportadas, aparecendo em } 13 \text { dos } 21 \text { trabalhos } \\
(62 \%) \text {. A xerostomia e a hipossalivação foram }\end{array}$ & $\begin{array}{l}\text { Esta revisão integrativa da literatura } \\
\text { apontou a presença de distúrbios } \\
\text { gustatórios e olfativos em pacientes } \\
\text { infectados pelo SARS-CoV-2, fazendo } \\
\text { com que tais sintomas devam ser } \\
\text { considerados uma importante suspeita da } \\
\text { infecção do paciente, como outros } \\
\text { estudos já indicaram. Ademais, apontou a }\end{array}$ \\
\hline
\end{tabular}


Research, Society and Development, v. 10, n. 7, e0710716081, 2021

(CC BY 4.0) | ISSN 2525-3409 | DOI: http://dx.doi.org/10.33448/rsd-v10i7.16081

\begin{tabular}{|c|c|c|c|c|c|c|}
\hline & & & & & sintomas que apareceram em seis estudos (29\%). & $\begin{array}{c}\text { ocorrência de xerostomia ou } \\
\text { hipossalivação associada à COVID-19. } \\
\text { Outras alterações bucais observadas em } \\
\text { alguns trabalhos foram ulcerações, que } \\
\text { também são manifestação muito comum } \\
\text { de infecções virais em boca. Estudos são } \\
\text { necessários para entender o real papel do } \\
\text { vírus na ocorrência dos sintomas que } \\
\text { foram levantados. }\end{array}$ \\
\hline $\begin{array}{l}\text { COVID-19 e a } \\
\text { Cavidade } \\
\text { Bucal: } \\
\text { Interações, } \\
\text { Manifestações } \\
\text { Clínicas e } \\
\text { Prevenção }\end{array}$ & 2020 & $\begin{array}{l}\text { ULAKES } \\
\text { Journal of } \\
\text { Medicine. }\end{array}$ & $\begin{array}{c}\text { Tiago Fernandes } \\
\text { Cardoso, Maria Júlia } \\
\text { Lima Eugenio Dias, } \\
\text { Marina Cavalcante } \\
\text { Chini, Bruna } \\
\text { Letícia Buzati Pereira, } \\
\text { Silvana Regina Perez } \\
\text { Orrico. }\end{array}$ & $\begin{array}{c}\text { Revisão de } \\
\text { literatura }\end{array}$ & $\begin{array}{l}\text { Diversas manifestações podem estar presentes na } \\
\text { cavidade bucal em pacientes com COVID-19, } \\
\text { sendo citadas a sialadenite aguda e crônica, } \\
\text { anosmia, ageusia e lesões ulceradas e/ou } \\
\text { vesiculobolhosas na mucosa de revestimento e no } \\
\text { palato. A infecção das glândulas salivares pelo } \\
\text { SARS-CoV-2 torna essas estruturas um potencial } \\
\text { reservatório do vírus para a saliva. A concentração } \\
\text { do vírus na saliva, entretanto, pode vir de outras } \\
\text { fontes além das glândulas salivares, como pulmões, } \\
\text { orofaringe, nasofaringe e bolsa periodontal. }\end{array}$ & $\begin{array}{l}\text { A cavidade bucal apresenta receptores } \\
\text { ECA2 em diversos sítios, o que a torna } \\
\text { uma possível porta de entrada ao SARS- } \\
\text { CoV-2. Diversas manifestações clínicas } \\
\text { foram diagnosticadas na cavidade bucal } \\
\text { em indivíduos com COVID-19 como } \\
\text { sialadenite, anosmia, ageusia e } \\
\text { ulcerações, dentre outras. A saliva pode } \\
\text { ser considerada um meio viável de } \\
\text { detecção de } \\
\text { SARS-CoV-2, podendo se tornar uma } \\
\text { importante via de testagem maciça da } \\
\text { população. Devido às características dos } \\
\text { procedimentos odontológicos, que podem } \\
\text { envolver a disseminação de partículas de } \\
\text { saliva e formação de aerossóis, uma } \\
\text { expressiva mudança na forma de } \\
\text { atendimento nos consultórios, com } \\
\text { instalação de efetivas medidas de }\end{array}$ \\
\hline
\end{tabular}


Research, Society and Development, v. 10, n. 7, e0710716081, 2021

(CC BY 4.0) | ISSN 2525-3409 | DOI: http://dx.doi.org/10.33448/rsd-v10i7.16081

\begin{tabular}{|c|c|c|c|c|c|c|}
\hline & & & & & & proteção, deve ser realizada. \\
\hline $\begin{array}{c}\text { Orofacial } \\
\text { manifestations } \\
\text { of COVID-19: } \\
\text { a brief review } \\
\text { of the } \\
\text { published } \\
\text { literature }\end{array}$ & 2020 & $\begin{array}{l}\text { CritiCal } \\
\text { review } \\
\text { Oral } \\
\text { Pathology }\end{array}$ & $\begin{array}{c}\text { Esam HALBOUB; } \\
\text { Sadeq Ali AL- } \\
\text { MAWERI; Rawan Hejji } \\
\text { ALANAZI; Nashwan } \\
\text { Mohammed QAID; } \\
\text { Saleem ABDULRAB }\end{array}$ & $\begin{array}{c}\text { Revisão } \\
\text { integrativa } \\
\text { da literatura }\end{array}$ & $\begin{array}{l}16 \text { artigos envolvendo } 25 \text { pacientes COVID-19- } \\
\text { positivos. Os resultados mostraram uma marcada } \\
\text { heterogeneidade nas manifestações orofaciais } \\
\text { associadas à COVID-19. As manifestações } \\
\text { orofaciais mais comuns foram lesões ulcerativas, } \\
\text { lesões vesiculobolhosas / maculares e sialadentite } \\
\text { aguda da glândula parótida (parotidite). Em quatro } \\
\text { casos, as manifestações orais foram os primeiros } \\
\text { sinais de COVID-19. }\end{array}$ & $\begin{array}{l}\text { Os pacientes com COVID-19 manifestam } \\
\text { certas características orofaciais que } \\
\text { podem ajudar os médicos a identificar } \\
\text { casos suspeitos. Isso inclui úlceras orais, } \\
\text { lesões vesiculobolhosas, máculas } \\
\text { eritematosas e parotidite aguda. No } \\
\text { entanto, parece que as manifestações } \\
\text { orais desta doença são subnotificadas, } \\
\text { principalmente por se tratar de uma } \\
\text { doença nova. }\end{array}$ \\
\hline $\begin{array}{c}\text { Salivary } \\
\text { Glands, Saliva } \\
\text { and Oral } \\
\text { Findings in } \\
\text { COVID-19 } \\
\text { Infection }\end{array}$ & 2020 & $\begin{array}{l}\text { Association } \\
\text { of Support } \\
\text { to Oral } \\
\text { Health } \\
\text { Research - } \\
\text { APESB }\end{array}$ & $\begin{array}{c}\text { Marlus da Silva } \\
\text { Pedrosa; Carla Renata } \\
\text { Sipert; Fernando Neves } \\
\text { Nogueira; }\end{array}$ & $\begin{array}{l}\text { Revisão } \\
\text { crítica }\end{array}$ & $\begin{array}{l}\text { A literatura mostra que o SARS-CoV-2 pode } \\
\text { infectar as glândulas salivares. Não é possível, } \\
\text { entretanto, fazer especulações a respeito deles } \\
\text { como reservatórios do SARS-CoV-2. }\end{array}$ & $\begin{array}{l}\text { A infecção por SARS-CoV-2 é } \\
\text { responsável por vários eventos na boca, } \\
\text { incluindo hipossalivação e alterações do } \\
\text { paladar. Alguns relatórios mostraram } \\
\text { úlceras orais e bolhas associadas à } \\
\text { infecção por SARS-CoV-2. No entanto, } \\
\text { ainda não é totalmente compreendido e } \\
\text { pode levar a suposições errôneas. Estudos } \\
\text { são necessários para compreender o real } \\
\text { papel das glândulas salivares e da saliva } \\
\text { neste contexto da doença. }\end{array}$ \\
\hline $\begin{array}{l}\text { Oral } \\
\text { Manifestations } \\
\text { of COVID-19 }\end{array}$ & 2020 & $\begin{array}{l}\text { Internationa } \\
\underline{\text { 1 Journal }} \\
\text { of OdontoS }\end{array}$ & $\begin{array}{l}\text { María Eugenia Nemeth } \\
\text { Kohanszky; Carolina } \\
\text { Paz Matus Abásolo; }\end{array}$ & $\begin{array}{l}\text { Revisão } \\
\text { descritiva }\end{array}$ & $\begin{array}{l}\text { As principais manifestações orais da COVID-19 } \\
\text { relatadas na literatura são: hipossalivação, } \\
\text { xerostomia, ageusia, hipogeusia, disgeusia, lesões }\end{array}$ & $\begin{array}{l}\text { É de grande relevância incorporar } \\
\text { rotineiramente a avaliação de sinais e } \\
\text { sintomas orais em pacientes com }\end{array}$ \\
\hline
\end{tabular}


Research, Society and Development, v. 10, n. 7, e0710716081, 2021

(CC BY 4.0) | ISSN 2525-3409 | DOI: http://dx.doi.org/10.33448/rsd-v10i7.16081

\begin{tabular}{|c|c|c|c|c|c|c|}
\hline & & $\underline{\text { tomatology }}$ & $\begin{array}{l}\text { Rolando Rafael } \\
\text { Carrasco Soto }\end{array}$ & & $\begin{array}{l}\text { herpéticas e candidíase. } \\
\text { A cavidade oral provou ser a porta de entrada } \\
\text { perfeita para a infecção por SARS-CoV-2 devido à } \\
\text { afinidade especial do vírus com os receptores } \\
\text { ECA2 presentes nas células da mucosa oral, língua } \\
\text { e glândulas salivares. Uma vez instalada a doença, } \\
\text { o vírus teria a capacidade de alterar o equilíbrio da } \\
\text { microbiota oral e imunossuprimir o paciente, } \\
\text { permitindo o possível aparecimento de infecções } \\
\text { oportunistas. Isso, aliado à terapia medicamentosa e } \\
\text { aos distúrbios das glândulas salivares, cuja } \\
\text { etiologia ainda não está totalmente esclarecida, } \\
\text { contribuiria para o desenvolvimento de } \\
\text { manifestações orais e distúrbios sensoriais, que } \\
\text { poderiam se apresentar precocemente e ser muito } \\
\text { úteis para a identificação diagnóstica oportuna } \\
\text { dessa patologia. }\end{array}$ & $\begin{array}{l}\text { diagnóstico de infecção por SARS-CoV-2 } \\
\text { para determinar se as manifestações orais } \\
\text { fazem parte da semiologia da infecção ou, } \\
\text { se correspondem, a diferentes entidades } \\
\text { patológicas. aqueles que são favorecidos } \\
\text { pela resposta imune desencadeada por } \\
\text { esse novo coronavírus, além de estimular } \\
\text { a higiene bucal adequada para reduzir o } \\
\text { risco de complicações como pneumonia e } \\
\text { SDRA. }\end{array}$ \\
\hline $\begin{array}{c}\text { COVID-19 and } \\
\text { oral lesions, } \\
\text { short } \\
\text { communication } \\
\text { and review }\end{array}$ & 2021 & $\begin{array}{l}\text { Journal } \\
\text { section: } \\
\text { Oral } \\
\text { Medicine } \\
\text { and } \\
\text { Pathology }\end{array}$ & $\begin{array}{c}\text { Sonia Egido-Moreno; } \\
\text { Joan Valls-Roca- } \\
\text { Umbert; Enric Jané- } \\
\text { Salas; José López- } \\
\text { López; Albert Estrugo- } \\
\text { Devesa }\end{array}$ & $\begin{array}{c}\text { Revisão de } \\
\text { literatura }\end{array}$ & $\begin{array}{l}\text { Os pacientes apresentaram uma grande variedade } \\
\text { de manifestações orais. As mais prevalentes foram } \\
\text { as lesões com solução de continuidade como } \\
\text { úlceras, lesões aftas ou erosões, seguidas de } \\
\text { máculas e petéquias, placas, bolhas; anomalias } \\
\text { gengivais, como gengivite descamativa e } \\
\text { necrosante e, finalmente, bolhas e pústulas. } \\
\text { A localização mais frequente foi na língua, seguida } \\
\text { do palato e lábio, gengiva, mucosa jugal e por fim a } \\
\text { comissura. }\end{array}$ & $\begin{array}{l}\text { Pode-se esperar que a doença COVID-19 } \\
\text { cause lesões cutâneas e mucosas, } \\
\text { provavelmente como manifestações } \\
\text { secundárias. }\end{array}$ \\
\hline Oral and & 2021 & Revista & Mayara faria de moraes; & Revisão de & As manifestações orais e cutâneas mais citadas & Erupções eritematosas nas extremidades \\
\hline
\end{tabular}


Research, Society and Development, v. 10, n. 7, e0710716081, 2021

(CC BY 4.0) | ISSN 2525-3409 | DOI: http://dx.doi.org/10.33448/rsd-v10i7.16081

\begin{tabular}{|c|c|c|c|c|c|c|}
\hline $\begin{array}{l}\text { cutaneous } \\
\text { manifestations } \\
\text { of covid-19 in } \\
\text { pediatric } \\
\text { patients }\end{array}$ & & $\begin{array}{l}\text { Gaúcha de } \\
\text { Odontologi } \\
\text { a }\end{array}$ & $\begin{array}{c}\text { Yasmim dos } \\
\text { reis natalino; } \\
\text { Andressa feller holanda; } \\
\text { Hellen ferreira de souza } \\
\text { sobrinho; } \\
\text { Lilian citty sarmento; } \\
\text { Ana paula } \\
\text { martins gomes; } \\
\text { Luciana faria sanglard }\end{array}$ & literatura & $\begin{array}{l}\text { foram, respectivamente, disfunção gustativa em } \\
\text { adolescentes e erupção eritematosa em } \\
\text { extremidades e tronco }\end{array}$ & $\begin{array}{l}\text { dos membros e tronco as mais comuns. } \\
\text { Em relação à manifestação na cavidade } \\
\text { oral, destaca-se a disfunção gustativa } \\
\text { relatada pelos adolescentes. }\end{array}$ \\
\hline $\begin{array}{c}\text { Oral } \\
\text { Manifestation } \\
\text { COVID-19 and } \\
\text { the Rapid } \\
\text { Resolution of } \\
\text { Symptoms } \\
\text { Post-Phtalox } \\
\text { Treatment: a } \\
\text { Case Series }\end{array}$ & 2021 & $\begin{array}{l}\frac{\text { Internationa }}{\underline{\text { Journal }}} \\
\underline{\text { of OdontoS }} \\
\underline{\text { tomatology }}\end{array}$ & $\begin{array}{l}\text { Bernardo da Fonseca } \\
\text { Orcina; Paulo Sérgio da } \\
\text { Silva Santos }\end{array}$ & $\begin{array}{l}\text { Carta ao } \\
\text { editor }\end{array}$ & $\begin{array}{l}\text { A cura completa das úlceras bucais ocorreu em } \\
\text { todos os pacientes com diagnóstico de COVID-19, } \\
\text { e a duração média da cura completa foi de 2,37 } \\
\text { dias. Também foi observada melhora geral dos } \\
\text { sintomas do COVID-19. }\end{array}$ & $\begin{array}{l}\text { Com base na rápida recuperação das } \\
\text { úlceras bucais observada, sugere que } \\
\text { Phtalox® é eficaz como um tratamento } \\
\text { oral complementar para úlceras } \\
\text { associadas à COVID-19. }\end{array}$ \\
\hline $\begin{array}{l}\text { Covid-19 and } \\
\text { oral diseases: } \\
\text { Crosstalk, } \\
\text { synergy or } \\
\text { association? }\end{array}$ & 2021 & $\begin{array}{l}\text { Reviews in } \\
\text { medical } \\
\text { virology }\end{array}$ & $\begin{array}{l}\text { Daniela A. Brandini; } \\
\text { Aline S. Takamiya; } \\
\text { Pari Thakkar; } \\
\text { Samantha Schaller; } \\
\text { Rani Rahat; } \\
\text { Afsar R. Naqvi }\end{array}$ & $\begin{array}{c}\text { Revisão da } \\
\text { literatura }\end{array}$ & $\begin{array}{l}\text { Úlceras, bolhas, gengivite necrosante, coinfecções } \\
\text { oportunistas, alterações das glândulas salivares, } \\
\text { placas brancas e eritematosas e disfunção gustativa } \\
\text { foram as manifestações clínicas orais mais relatadas } \\
\text { em pacientes com Covid - 19. Em geral, as lesões } \\
\text { aparecem concomitantes com a perda do olfato e do } \\
\text { paladar. }\end{array}$ & $\begin{array}{l}\text { É altamente recomendável que os } \\
\text { profissionais de saúde realizem um exame } \\
\text { oral detalhado com atenção extra às } \\
\text { manifestações orais para garantir o } \\
\text { suporte ao paciente e o controle da dor. }\end{array}$ \\
\hline
\end{tabular}

Fonte: Autores. 
Research, Society and Development, v. 10, n. 7, e0710716081, 2021

(CC BY 4.0) | ISSN 2525-3409 | DOI: http://dx.doi.org/10.33448/rsd-v10i7.16081

Em geral, as lesões aparecem concomitantes com a perda do olfato e do paladar. A análise dos 13 trabalhos mostrou a presença de úlceras, erosões, bolhas, vesículas, pústulas, língua fissurada, máculas, pápulas, halitose, candidíase, parotidite, petéquias, gengivite ulcerativa necrosante, xerostomia e hipossalivação. Além disso, disgeusia, ageusia, hipogeusia foram alterações comumente presentes. A localização mais frequente foi na língua, seguida do palato e lábio, gengiva, mucosa jugal e por fim a comissura.

A cavidade oral provou ser a porta de entrada perfeita para a infecção por SARS-CoV-2. Uma vez instalada a doença, o vírus teria a capacidade de alterar o equilíbrio da microbiota oral e imunossuprimir o paciente, permitindo o possível aparecimento de infecções oportunistas. Isso, aliado à terapia medicamentosa e aos distúrbios das glândulas salivares, contribuiria para o desenvolvimento de manifestações orais e distúrbios sensoriais.

\section{Discussão}

Pacientes com coronavírus apresentaram algumas lesões orais, tais como gengivite, disgeusia, petéquias, candidíase oral e ulcerações. Entretanto, não se sabe se essas lesões são advindas d Covid-19 ou se são reações adversas causadas por fármacos utilizados no tratamento da doença ou se são originadas pela coinfecção e imunidade baixa (Orcina \& Santos, 2021).

Dos Santos et al. selecionaram estudos observacionais e relatos de caso que analisaram a prevalência de manifestações orais nos pacientes com SARS-CoV- 2. Lesões orais esbranquiçadas, úlceras, nódulos, língua geográfica, língua fissurada, saliva viscosa, superfícies eritematosas, gengivite e máculas foram algumas das lesões que apareceram nas pesquisas. Entretanto, desordens no paladar foram os sintomas bucais mais recorrentes entre os pacientes com Covid-19, sendo comumente encontradas nas fases mais brandas e moderadas da doença e em pacientes do sexo feminino, confirmando ser esse um sintoma específico dessa apresentação da referida patologia.

Os receptores da enzima conversora de angiotensina 2 (ECA2), presentes em diversos sítios da cavidade bucal, representam uma potencial via de entrada e propagação do SARS-coV-2 para o organismo (Cardoso, Dias, Chini, Pereira \& Orrico, 2020). Segundo Taques et al. (2020) a xerostomia e a hipossalivação são apresentadas como sintomas relacionados à infecção viral por Covid-19. Enquanto a formação de saliva está intimamente ligada ao paladar, a perda deste pode explicar tal fator; outra hipótese estudada é a sua ocorrência de forma secundária a congestão nasal e rinorréia, devido à respiração bucal (Knight, 1995).

Nas células epiteliais das glândulas salivares, a expressão elevada dos receptores ECA2, podem levar a uma potencial infecção, como a sialadenite aguda, que caso evolua, pode resultar em sialadenite crônica, decorrente da destruição tecidual glandular causado pelo processo inflamatório (Cardoso et al., 2020; Pedrosa, Sipert \& Nogueira, 2020).

A anosmia e augesia são geralmente relatadas na fase inicial da infecção por Covid-19, facilitando o diagnóstico. Estas acometem em torno de $15 \%$ dos pacientes, com maior frequência em mulheres e indivíduos jovens, normalmente, durante o período de sete dias. A ageusia pode ser explicada pela grande expressão dos receptores da ECA2 presentes nas células epiteliais da mucosa oral, principalmente na língua, podendo o dano gerado pela infecção ocasionar a disfunção. Outro tecido bastante afetado, é o epitélio olfatório, cujo dano provocado pelo vírus pode explicar a anosmia nos estágios iniciais (Cardoso et al., 2020).

A literatura relata lesões ulceradas na cavidade bucal com características semelhantes às encontradas na estomatite herpética ligadas diretamente ou de forma secundária a infecções virais (Santosh \& Muddana, 2020). Lesões vesiculobolhosas também são encontradas em pacientes infectados (Katz \& Yue, 2021; Kitakawa, Oliveira, Castro \& Carvalho, 2020; Maciel et al., 2020), associadas ao rash cutâneo, sugestivo de dermatite urticariforme ou lesões enxatemáticas virais. 
Research, Society and Development, v. 10, n. 7, e0710716081, 2021 (CC BY 4.0) | ISSN 2525-3409 | DOI: http://dx.doi.org/10.33448/rsd-v10i7.16081

Outra manifestação ligada, principalmente, à baixa imunidade e relatada em pacientes com infectados com Covid-19 é a estomatite aftosa recorrente. Xu et al. (2020) também apontam os receptores da ECA2 presentes na mucosa oral como principal fator para explicar tal ocorrência.

Os estudos de Gómez (2020) e Vieira (2020) correlacionam a periodontite moderada à grave, com piores prognósticos dos casos de Covid-19, devido ao estado inflamatório persistente nos tecidos de sustentação e proteção, gengivais, que desencadeiam a cascata da coagulação e aumentam os níveis de produtos da degradação do fibrinogênio, como o dímero. Casos de periodontite necrotizante aguda também são citados sendo relacionados a co-infecções bacterianas que ocorrem no ambiente intrabucal dos pacientes.

A teleodontologia surge como uma alternativa para consultas e triagem remota. Pode ser usada para uma variedade de procedimentos, como a orientação de higiene bucal, diagnóstico e tratamento de algumas condições bucais que não necessitem do atendimento em consultório. Entretanto, esta ferramenta deve ser utilizada com cautela e dentro das suas limitações pelo profissional. (Jotz et al., 2020)

Após uma procura nas bases de dados online e análise dos artigos é possível constatar que há uma forte evidência do aparecimento de alterações bucais relacionadas ao indivíduo acometido pela Covid-19. Logo, é preciso reforçar a importância da presença do cirurgião dentista na equipe multiprofissional em ambiente hospitalar para identificação do surgimento dessas possíveis patologias e tratamento precoce destas.

\section{Considerações Finais}

Foi possível associar o surgimento de manifestações bucais com a Covid-19. Não se tem comprovação se são alterações secundárias ao tratamento ou se estão diretamente relacionadas ao coronavírus. Sendo assim, necessários mais estudos para concluir se as manifestações orais são secundárias ou se estão diretamente interligadas ao vírus.

A presença do cirurgião dentista é de grande importância na equipe multiprofissional durante e após o tratamento do paciente com Covid-19, a fim de oferecer um tratamento e reabilitação mais adequados e satisfatórios.

\section{Referências}

Al-Khanati, N. M., Riad, A., Sahloul, M. E., \& Klugar, M. (2020). Aphthous-like stomatitis of COVID-19 patients: case report and review of evidence. Brazilian Journal of Oral Sciences, 19.

Brandini, D. A., Takamiya, A. S., Thakkar, P., Schaller, S., Rahat, R., \& Naqvi, A. R. (2021). Covid-19 and oral diseases: Crosstalk, synergy or association?. Reviews in Medical Virology.

Cardoso, T. F., Dias, M. J. L. E., Chini, M. C., Pereira, B. L. B., \& Orrico, S. R. P. (2020). COVID-19 e a Cavidade Bucal: interações, manifestações clínicas e prevenção. ULAKES JOURNAL OF MEDICINE, 1.

Egido-Moreno, S., Valls-Roca-Umbert, J., Jané-Salas, E., López-López, J., \& Estrugo-Devesa, A. (2021). COVID-19 and oral lesions, short communication and review. Journal of Clinical and Experimental Dentistry, 13(3), 287-294.

Giudice R. L. (2020). The Severe Acute Respiratory Syndrome Coronavirus-2 (SARS CoV-2) in Dentistry. Management of Biological Risk in Dental Practice. International journal of environmental research and public health, 17(9), 3067.

Gómez, J. L. M. (2020). COVID-19 y su trascendencia en la atención dental: revisión y actualización de la literatura. Odontología sanmarquina, 23(3), 261270 .

Halboub, E., Al-Maweri, S. A., Alanazi, R. H., Qaid, N. M., \& Abdulrab, S. (2020). Orofacial manifestations of COVID-19: a brief review of the published literature. Brazilian oral research, 34 .

Iranmanesh, B., Khalili, M., Amiri, R., Zartab, H., \& Aflatoonian, M. (2021). Oral manifestations of COVID-19 disease: A review article. Dermatologic therapy, 34(1), 14578

Jotz, G. P., Stein, A., Sirena, S., Barros, E., Baldisserotto, J., Figueiredo, J. A. P. D., \& Dora, C. (2020). The COVID-19 Pandemic and Planetary Health. A Critical Review of Epidemiology, Prevention, Clinical Characteristics and Treatments for Oral, Head and Neck Health Professionals. Do We Have a Roadmap?. International archives of otorhinolaryngology, 24(3), 351-358. 
Research, Society and Development, v. 10, n. 7, e0710716081, 2021 (CC BY 4.0) | ISSN 2525-3409 | DOI: http://dx.doi.org/10.33448/rsd-v10i7.16081

Katz, J., \& Yue, S. (2021). Increased odds ratio for COVID-19 in patients with recurrent aphthous stomatitis. Journal of Oral Pathology and Medicine, 50(1), 114-117. https://doi.org/10.1111/jop.13114

Kitakawa, D., Oliveira, F. E., Neves De Castro, P., \& Carvalho, L. F. C. S. (2020). Short report - Herpes simplex lesion in the lip semimucosa in a COVID-19 patient. European Review for Medical and Pharmacological Sciences, 24(17), 9151-9153. https://doi.org/10.26355/eurrev_202009_22863

Lechien, J. R., Chiesa-Estomba, C. M., Siati, D. R. de, Horoi, M., Bon, S. D. L., Rodriguez, A., \& Saussez, S. (2020). Olfactory and gustatory dysfunctions as a clinical presentation of mild-to-moderate forms of the coronavirus disease (COVID-19): a multicenter European study. European Archives of Oto-RhinoLaryngology, 277(8), 2251-2261.

Li, L. Q., Huang, T., Wang, Y. Q., Wang, Z. P., Liang, Y., Huang, T. B., \& Wang, Y. (2020). COVID-19 patients' clinical characteristics, discharge rate, and fatality rate of meta-analysis. Journal of medical virology, 92(6), 577-583.

Li, Q., Guan, X., Wu, P., Wang, X., Zhou, L., Tong, Y., \& Leung, K. S. M. (2020). Early Transmission Dynamics in Wuhan, China, of Novel CoronavirusInfected Pneumonia. N Engl J Med, 382, 1199-1207.

Li, X., Xu, S., Yu, M., Wang, K., Tao, Y., Zhou, Y., \& Zhao, J. (2020). Risk factors for severity and mortality in adult COVID-19 inpatients in Wuhan. Journal of Allergy and Clinical Immunology, 146(1), 110-118.

Lucena, T. M. C. de, Santos, A. F. da Silva, Lima, B. R. de, Borborema, M. E. de A, \& de Azevêdo Silva, J. (2020). Mechanism of inflammatory response in associated comorbidities in COVID-19. Diabetes \& Metabolic Syndrome: Clinical Research \& Reviews, 14(4), 597-600.

Maciel, P. P., Martelli Júnior, H., Martelli, D. R. B., Machado, R. A., Andrade, P. V. D., Perez, D. E. D. C., \& Bonan, P. R. F. (2020). Covid-19 pandemic: Oral repercussions and its possible impact on oral health. Pesquisa Brasileira em Odontopediatria e Clínica Integrada, 20.

Moraes, M. F. D., Natalino, Y. D. R., Holanda, A. F., Souza Sobrinho, H. F. D., Sarmento, L. C., Gomes, A. P. M., \& Sanglard, L. F. (2021). Oral and cutaneous manifestations of covid-19 in pediatric patients. RGO-Revista Gaúcha de Odontologia, 69.

Nemeth-Kohanszky, M. E., Matus-Abásolo, C. P., \& Carrasco-Soto, R. R. (2020). Manifestaciones Orales de la Infección por COVID-19. International Journal of Odontostomatology, 14(4), 555-560. https://doi.org/10.4067/s0718-381x2020000400555

Oliveira Stroparo, J. L. de, Lyra, L. A. D. O. P., Abuabara, A., Andrades, K. M. R., Madalena, I. R., Küchler, E. C., \& Deliberator, T. M. (2021). Manifestações orais em pacientes infectados com sars COV-2. Brazilian Journal of Development, 7(4), 35984-35993.

Orcina, B. da F., \& Santos, P. S. da S. (2021). Oral Manifestation COVID-19 and the Rapid Resolution of Symptoms Post-Phtalox Treatment: a Case Series. International Journal of Odontostomatology, 15(1), 67-70. https://doi.org/10.4067/s0718-381x2021000100067

Ouassou, H., Kharchoufa, L., Bouhrim, M., Daoudi, N. E., Imtara, H., Bencheikh, N., Elbouzidi, A., \& Bnouham, M. (2020). The Pathogenesis of Coronavirus Disease 2019 (COVID-19): Evaluation and Prevention. Journal of Immunology Research, 2020. https://doi.org/10.1155/2020/1357983

Parra-Sanabria, E. A., Bermúdez-Bermúdez, M., Peña-Vega, C. P., \& Rueda-Jiménez, A. (2020). Manifestaciones orales y maxilofaciales asociadas a la COVID-19. Revisión de la literatura. Acta Odontológica Colombiana, 10(Supl COVID-19), 60-80. https://doi.org/https://doi.org/10.15446/aoc.v10n3.89447

Rothan, H. A., \& Byrareddy, S. N. (2020). Since January 2020 Elsevier has created a COVID-19 resource centre with free information in English and Mandarin on the novel coronavirus COVID-19. The COVID-19 resource centre is hosted on Elsevier Connect, the company 's public news and information . January.

Sampson, V., Kamona, N., \& Sampson, A. (2020). Could there be a link between oral hygiene and the severity of SARS-CoV-2 infections? British Dental Journal, 228(12), 971-975. https://doi.org/10.1038/s41415-020-1747-8

Sanglard, L. F. (2021). em pacientes pediátricos. 1-8.

Santosh, A. B. R., \& Muddana, K. (2020). Viral infections of oral cavity. Journal of family medicine and primary care, 9(1), 36.

Taques, L., Bortoluzzi, M. C., Karpinski, B. C., Brigola, S., Mattos, J. C. de, \& Rodachinski, P. (2020). Alterações do sistema estomatognático frente À COVID-19 - uma revisão integrativa / Changes in the stomatognathic system in face of COVID-19 - an integrative review. Brazilian Journal of Health Review, 3(6), 18600-18615. https://doi.org/10.34119/bjhrv3n6-252

Vieira, A. R. (2021). Oral manifestations in coronavirus disease 2019 (COVID-19). Oral Diseases, 27(S3), 770. https://doi.org/10.1111/odi.13463

Wang, C., Horby, P. W., Hayden, F. G., \& Gao, G. F. (2020). A novel coronavirus outbreak of global health concern. The Lancet, 395(10223), 470-473. https://doi.org/10.1016/S0140-6736(20)30185-9

Xu, H., Zhong, L., Deng, J., Peng, J., Dan, H., Zeng, X., Li, T., \& Chen, Q. (2020). High expression of ACE2 receptor of 2019 -nCoV on the epithelial cells of oral mucosa. International Journal of Oral Science, 12(1), 1-5. https://doi.org/10.1038/s41368-020-0074-X. 